\title{
Problems of the formation of marketing communications in the field of management of logistics systems
}

\author{
Gela Mamuladze $^{1 *}$, Davit Katamadze ${ }^{1}$, Guliko Katamadze ${ }^{1}$, Giorgi Mamuladze ${ }^{1}$, and Ivane \\ Bakuradze $^{1}$ \\ ${ }^{1}$ Batumi Shota Rustaveli State University, 32/35 Rustaveli/Ninoshvili st. Batumi, 6010, Georgia
}

\begin{abstract}
The article considers the problems in the field of logistic system management and analyzes the role of marketing communications in solving these problems. Based on the research, it was found that marketing communications can improve the connections established between the individual links of the logistics chain, which determines the effectiveness of the entire economic system and the degree of integration. Relevant research has not been conducted yet in the country, therefore, effective utilization of the concluded recommendations will help to raise the level of management of transport hubs in Georgia. The results of the study can be used by companies working in the field of international maritime transport, air, rail and road. It is assumed that if European and Asian producers increase the shipment of their products through our country from Europe to Asia or vice versa, the effective use of Georgia's transit capacity (function) will be guaranteed. The methodological basis of the article is bibliographic studies of Georgian and foreign scientists in the field of logistics systems management and marketing, data collection, observation, survey (in-depth interview). The method of data collection is mainly used in local logistics companies, where the situation with the use of marketing communications was analysed.
\end{abstract}

\section{Introduction}

Marketing communications in logistics companies can be established in informational, direct, reversible, and other forms. In order to build relationships with freight owners (or users of transportation services) logistics companies often use direct marketing, public relations and advertising. In logistics systems, the connection between transportation and warehouse companies is much closer than their connection to other (external) economic systems. Establishing a flexible marketing communication mechanism between the supplier and the customer is extremely important for the effective management of the logistics system. Effective marketing communications should ensure an increased level of integration of transport channels. The low efficiency of the logistics systems in Georgia is explained by the low level of marketing communications between its transport channels (rail, road, sea and air) [5].

\footnotetext{
${ }^{*}$ Corresponding author: mamuladze.gela@bsu.edu.ge
} 
Improving the management of the logistics system requires the establishment of a close relationship between its constituent structural elements, which should lead to a high level of integration and organization. Representatives of commerce, logistics and marketing are involved in a unified process of logistics system management. The exchange of manufactured products, their placement in wholesale, retail networks and sales is the common goal of their activities. The involvement of stakeholders in the process of distribution-exchange of goods is profit-oriented, which is characterized by elements of commerce, marketing and logistics [8].

For the research, we examined the activities of $15 \mathrm{~B} 2 \mathrm{~B}$ products and service companies operating in Georgia, from $15^{\text {th }}$ of January to $10^{\text {th }}$ of April, 2021. Also, taking into account the interests of the research, the views of representatives of various logistics companies were analyzed.

Management of the logistics system includes the control of the movement and placement of material flows, the integration of the individual logistics process into unified system to minimize the delivery time of the goods to the right place at a low cost. However, the challenge is that unified system requires the mutual economic interests of the individual entities. Under such conditions, it will be possible to achieve a result-oriented approach to the process of movement of goods.

A comprehensive logistics approach to transportation management supports optimization of the cargo flows, reducing the overall cost of freight. In addition to reducing costs in the delivery and shipping processes, it is necessary to reduce costs in the packaging of goods. The retail chain needs to establish a direct partnership between all participants in the logistics process.

One of the ways of proper management of the logistics system represents periodic, continuous updating of marketing communications between its components (warehouses and transport nodes). This goal can be achieved by providing technical, technological, economical and mathematical solutions to existing problems in the field of marketing communications, which ensures the proper management of the logistics system.

To improve the management of logistics systems and control the movement of goods, managers need to simultaneously plan the movement of material flows as well as organize operations and inventories [10].

Planning of material flows includes the control of the logistics company budget, operational and calendar planning of transportation processes, warehouse network, control of information systems and production of final products. Inventory management includes demand forecasting, control and management of inventories of finished products, semifinished products, raw materials.

\section{The results of the research and discussion}

If the development strategies of the individual logistics companies are well aligned and successfully heading toward a common goal, this integration will lead to a more thorough result than the uncoordinated use of marketing communications. If the marketing approaches of the individual parties involved in the logistics chain are not unified in handling common challenges, the potential customers might be lost. The lack of such coordination in many Georgian logistics companies creates the compatibility problem in the marketing approach [2]. For example, transport companies may emphasize the efficient and in time delivery of goods, while warehouse managers may underline safe storage of goods. How will these different approaches in marketing communications create a sustainable and solid logistics system and strengthen its position in the market? 
An uncoordinated approach in marketing communications is destructive for a logistics company and negatively affects its image, competitiveness. Especially if the marketing messages carry contradictory information.

For example, if a logistics company offers improvement of safe handling of the goods, on the one hand, and reduced freight rate will lead to losing their trust within the customers.

One of the indications of marketing communication issues among the logistics companies is a dissimilarity in the tariff policy. The transportation tariff, as an economic category, includes the cost of cargo delivery, which should provide coverage of operating costs and generate a certain profit. One of the factors influencing the choice between available delivery options is the cost of delivery. If there is an opportunity for alternative freight routes between countries, it is possible to revise transport and tariff policies in terms of reducing delivery costs.

It can be achieved as a result of the development of competition [9]. For example, in the case of alternative transit routes between Iran and Azerbaijan-Armenia is developed in the area of freight flows between the regions of Europe and Asia, Georgia faces serious competition. Due to the territorial conflict between Azerbaijan and Armenia over the Karabakh and the negative attitude of the US and Western European countries with Iran because of the construction of nuclear power plant, Georgia has had the opportunity of full utilization of its transit function. However, considering the fact that relation with Iran is improving, this opportunity has slightly decreased.

Most likely, the current situation will reduce the volume of transited cargo through Georgia. This is based on an analysis of data provided by the Ministry of Economy and Sustainable Development of Georgia on Georgia's transport channels in 2016-2020 [9, 1113].

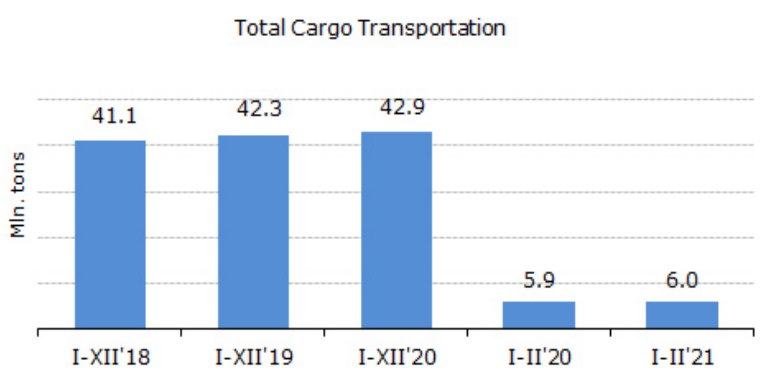

Fig 1. Total Cargo Transportation [13].

As shown in Figure 1, the amount of cargo transported by Georgia's transportation sectors from 2016-2020 was steady at 41.1 million to 42.9 million tons. Despite the spread of the COVID-19 pandemic around the world in 2020 (including Georgia), the amount of cargo transported through Georgia's has increased by 0.6 million tons, compared to the same figure in 2019.

In order to harmonize the marketing communications within the transport hubs of Georgie, it is necessary to unify and synchronize tariff policies. It should be noted that processing cargo flows through the country for certain time is supported by long-term contracts which are usually agreed between European and Asian suppliers and logistics companies operating in Georgia. In addition, freight tariffs can be maintained at a relatively high level by creating demand for additional shipment services [4]. In fact, the Georgia Department of Transportation had significantly reduced the protection and accompanying tax in February of 1994, which increased demand for services. As a result, the total amount of transported goods was increased. 
Different types of transport channels have completely different tariff systems. In particular, common, special, preferential and local tariffs are used to determine the cost of cargo transported by rail in Georgia. The cost of the transportation of bulk cargo is determined by the common tariff.

Special tariffs are derived from general tariffs with a special surcharge or discount, which is applied to a particular freight flow and affects the development of Georgia's industry so that it can help regulate the inter-industry balance of the economy. The special tariff can be used to maintain the same transportation time by railroad at different seasons of the year. Reduced tariffs on damaged cars and containers serve the same purpose. The preferential tariff is used for special purpose freight - transportation by rail. Local communication tariffs are set by the heads of railroad departments. These tariffs include the amount of freight and rates of the various sets operating on that railroad. In addition to the cost of delivery, the railroad charges the shipper and consignee for additional transportation services. This charge is called a bundle and is charged for the following railroad operations: storage, weighing and inspection of cargo, delivery and cleaning of wagons, disinfecting them, forwarding, loading and unloading.

The amount of the freight tariff by rail is determined by the following criteria: 1 . Type of cargo (wheat, oil, furniture, car); 2. Volume of cargo flow; 3. Type of wagon (universal, specialized or insulated wagon, container, tanker, platform); 4. Wagon capacity (60 tons, 25 tons, 10 tons); 5. Delivery speed (freight, oversized and passenger); 6. Delivery distance; 7. Owner of the vehicle (railroad, consignee, shipper) and others.

Transportation of goods by road is taxed at the following rates: freight rate; Price per ton/hour, distance rate, tariff agreement. Trucking rates are affected by the range, weight, and volume of the cargo. The capacity of the vehicle must be considered in determining the rate for transported goods based on following indicators: total distance, time of usage of the vehicle, type of vehicle, area in which the shipment occurs, and other factors. When transporting goods by trucks, each tariff does not take into account the entire set of factors, but some of them that apply in the case of a particular shipment. For example, to calculate the cost of delivery by freight rate close attention should be paid to the weight and class of cargo, which characterize the capacity of the vehicle, as well as its use and total milage. In all cases, the tariff is affected by the area of shipment. It explains the difference in the cost of freight delivery by region, which is adjusted by a correction factor.

As regards the freight rate for the goods transported by sea, it is determined by the factors, such as: area of trading, types of cargo, the amount of the cargo, types of the ship used, etc. For liner shipping that transports the goods at regular routes on fixed schedules, the freight rate is preliminary stated. On the other hand, for the tramp services that is a ship that has no fixed routing or itinerary or schedule and is available at short notice (or fixture) to load any cargo from any port to any port, the cost of transportation is set at the freight rate.

In logistics hubs, where cargo is transported by several types of transport mode, the supplier has to deal with and pay multiple rates separately [7]. Therefore, by using proper marketing communication with representatives of different parts of the logistics system, the supplier will be able to negotiate over the key aspects of the transportation, such as, to improve the safety of freight flow, to schedule, choose place and time, reduce delivery costs. At the same time, the cargo owner can choose the logistics company according to the quality, efficiency, safety and delivery rate, and change the types of transport from one point to another to make the best combination. In this respect, those transit countries and logistics companies which can simultaneously offer several types of transport means and routes, have a higher level of competitive advantage, as this allows customers to choose more alternative freight transport that simplifies their task. 


\section{Discussions}

At the present moment, in the context of globalization and internationalization of the world economy, improvement of the management of logistics systems requires the development of a high level of marketing communications and the use of marketing intermediaries in the transport channels. The advanced marketing communications between individual elements of logistics systems will help accelerate the turnover of invested capital. Effective marketing communications play an important role in the exchange and distribution of information, financial and material flows of products. Intermediaries by using effective marketing communication tools will be able to support the synchronization, harmonization and unification of cargo flow as well as identification of challenges in logistics hubs.

In order to identify the existing problems in the field of marketing communications in logistics systems, a qualitative research has been conducted - through surveys and in-depth (telephone) interviews. Within the framework of the research, 15 logistics companies operating in Georgia were selected. The results of a qualitative survey showed that logistics companies are failing to properly utilize the potential of marketing communications.

From this point of view, it was interesting the opinion of logistics companies concerning the development of the logistics industry in Georgia. According to the survey, $66.7 \%$ of respondents believe that the sector is "partially developed", while $22,2 \%$ and $11.1 \%$ of respondents claim as „developed" and "not developed”, respectively.

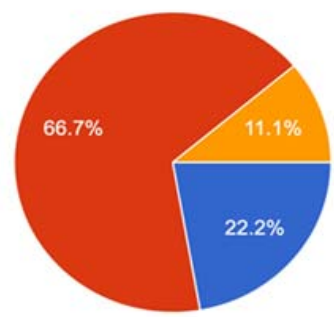

Peveloped

Not developed

Fig. 2. Respondents' views towards the development of the logistics market in Georgia.

In order to study the research topic in detail, it was necessary to determine what factors hold back the development of the logistics market. According to the survey, the majority of respondents $(66.7 \%)$ consider the problem to be the "lack of appropriate personnel". it is followed by the "lack of appropriate infrastructure", the third - "legal framework", the fourth - "lack of adequate financial resources", the fifth - "low level of transport development," and the sixth - "low level of warehousing.

The research revealed the necessity to identify factors constraining the development of logistics companies. The results of the study showed that the most negative impact on the development of logistics companies has a "Covid pandemic" (66,7\%). In terms of impact, it is followed by "changes in the Georgian national currency GEL exchange rate", the third place by "high transport tariffs", and the fourth one by "tax tariffs".

Besides, the identification of factors dependent on freight rates, is under a spotlight. According to $77.8 \%$ of the respondents, freight rates depend on a distance. In terms of influence on freight rates, the second place is held by "cargo type", the third place by "cargo quantity" and the fourth one by "shipping time".

It was also interesting to determine the factors that define the logistics companies' competitive advantage. The majority of respondents $(66.7 \%)$ consider such factor as "time". As regards to the rest factors, such as "opportunities", "productivity", "resources" and "result", the respondents perceive as same. Respondents give relatively less importance to "skills" and "costs". 
Another circumstance was revealed as the need to identify the measures taken by companies to improve their reputation. All respondents clearly stated that "reliability" and "adequacy of price/quality" were the most important in this regard. They are followed by "integrity", then "access to information", fifth and sixth places by "charity" and "loyalty". None of the respondents considered usage of "sponsorship event" to enhance their reputation.

It was also interesting to note the attitude of logistics companies towards the use of marketing communication forms. In this case, as in the previous question, all respondents prefer "phone" and "e-mail" approach. "Website" (44,4\%) holds the second place, the third place - "social networks", fourth and fifth places - "chat" and "Skype", respectively.

The research revealed another key element: it was interesting to know to what extent logistics companies use marketing communication tools in their activities? (Figure 3). $44.4 \%$ of respondents said they "do not use" at all, $44.4 \%$ use these tools partially, and $11.1 \%$ use them systematically.
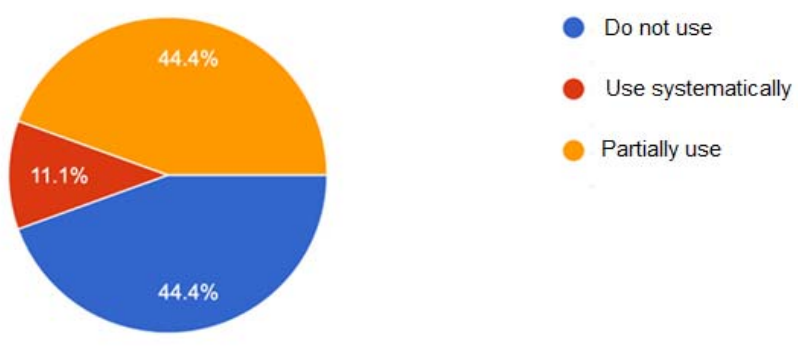

Fig. 3. Respondents' attitudes towards the use of marketing communication tools.

Source: The authors' research.

The research also showed interesting reasons why logistics companies refuse to use marketing communications, the survey results showed that $57.1 \%$ of respondents reject to use marketing communications due to their inefficient application. Others refuse because the use of these tools requires significant financial expenses.

In this regard, it was interesting to find out what marketing communication tools are most often used by the logistics companies we surveyed (Figure 4). The survey showed that $42.9 \%$ of respondents use "direct sales," $42.9 \%$ use public relations (PR), and $14.3 \%$ use advertising. None of them use "sales incentives".
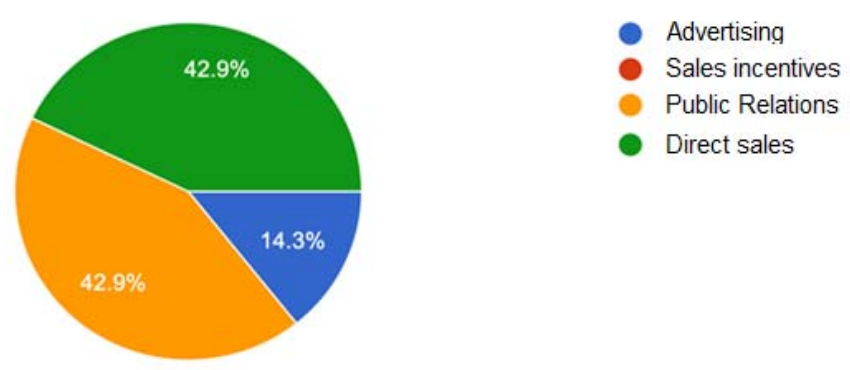

Fig. 4. Marketing communication tools used by logistics companies.

The survey presents an interesting overview of how logistics companies operating in Georgia have used advertising as an effective tool for marketing communications (Figure $5)$. 
The survey found out that $71.4 \%$ of respondents most often used email as an advertising tool, $14.2 \%$ used catalog distribution, and $14.2 \%$ used none of the above. Surprisingly, not a single company uses Internet and media advertising tools.
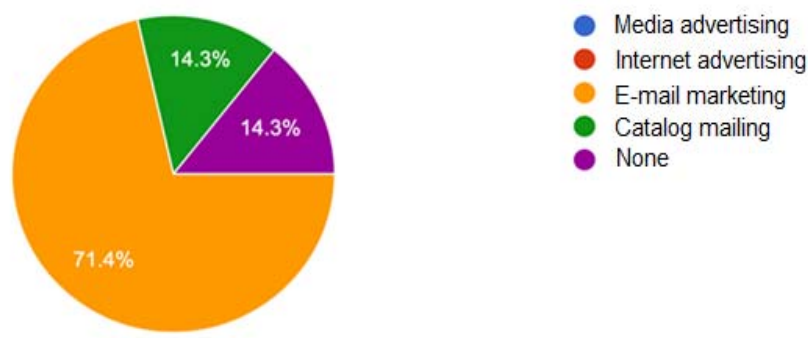

Fig. 5. The use of advertising by logistics companies as a tool for information distribution.

To fully analyze the current challenges, it was necessary to determine to what extent logistics companies in Georgia used PR as a marketing tool (Figure 6). The survey showed that Annual reports (20\%), Seminars (20\%), Presentation (20\%) and charitable activities $(20 \%)$, were evenly used, while the rest $20 \%$ do not use any of the above tools. Surprisingly, not a single company uses the press as a public relations (PR) tool. These and similar factors indicate that marketing communication tools are not properly implemented in the management of Georgia's logistics system.
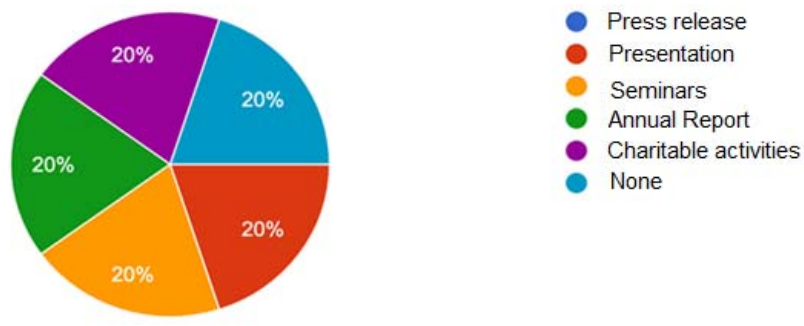

Fig. 6. The use of PR-mailing by logistics companies.

Besides, it was interesting to specify how logistics companies use direct marketing in their activities as a tool to promote their brand. The survey showed that $75 \%$ of respondents use email marketing and $25 \%$ use telephone marketing. As for catalog sales, none of the respondents use them as a direct marketing tool (see Chart 7).

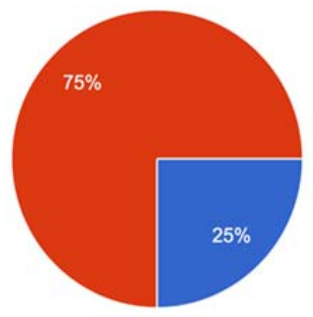

Catalog sale

Fig. 7. The use of direct marketing as a distribution tool by logistics companies. 
As for the second part of the survey (in-depth interview), the telephone interview showed that the logistics companies did not have their marketing department, dedicated for market research, attraction of cargo flows, and independent pricing policy. They delegate these functions to specialized intermediary marketing companies, which receive quite substantial amounts of money (almost half the cost of orders) for attracting freight flows and working with customers. It is assumed that instead of involving intermediary marketing companies for customer attraction, marketing departments in companies would make better output for attracting freight owners, forming and promoting the company reputation. Achieving this goal would require less financial resources than the amounts paid for the services provided by intermediary marketing companies [14-16]. Adopting these additional incentives would allow them to increase the number of costumers. This recommendation proved to be accountable to them. Therefore, the logistics companies that participated in the survey intend to take this into account.

\section{Conclusions}

Thus, the management of logistics companies operating in Georgia can become sophisticated by improving marketing communications, minimizing the material, financial and time costs of shipping and placing goods in the transportation and warehousing network. To achieve this goals, it is essential to:

1. Increase the special knowledge in the field of marketing among employees of logistics companies, train their managers in the principles of marketing management;

2. Create marketing departments and provide them with appropriate personnel;

3. Introduce effective marketing communication tools that will help raise the company's reputation and gain a competitive advantage;

4. Carry out systematic marketing research to ensure the reliability of the information available in the market and develop the right strategy

5. Actions related to the distribution of goods should be coordinated between the parties (a separate part of the logistics system);

6. It is necessary to choose the technological means of goods transportation correctly and rationally. The process of the cargo flow should always be coordinated between the participants in order to organize the technical side of the logistics system;

7. Optimize the workload of the logistics network, thus reduce costs and improve economic efficiency.

As a result of the above measures, it is possible to integrate the material flow system and proper management, which will ultimately ensure the successful development of logistics systems in Georgia and increase economic efficiency.

\section{References}

1. Xiangliana, C., \& Huab, L. (2013). Research on e-commerce logistics system informationization in Chain. 13th COTA International Conference of Transportation Professionals (CICTP 2013). Procedia - Social and Behavioral Sciences, 96, 838 - 843.

2. Gochava, D. (2015). Logistics system efficiency and Georgia. Journal "Transport and Logistics", Tbilisi, December.

3. Sheverdashvili, E., \& Totikashvili, S. (2017). The role of logistics in the development of the Georgian economy. Journal "Economy - XXI Century", Tbilisi.

4. Doborjginidze, G. (2014). The role of logistics in the development of the Georgian economy. Journal of Economics, 1-2. 
5. Makharadze, L. (2019). Logistics in the Georgian economy. Journal "Transport and Logistics", Tbilisi.

6. Osadze, L. (2009). The role of the logistics system in the economic activity of firms. Magazine. "Business and Management", 1, Batumi.

7. Kvlividze, N. (2020). Problems of creating a logistics cluster in Georgia. Journal "Transport and Logistics", 2, Tbilisi.

8. Brah, S.A, \& Lim, H.Y. (2006). The effects of technology and TQM on the performance of logistics companies. International Journal of Physical Distribution \& Logistics Management, 36(3), 192-209.

9. Laric, M.V., Lynagh, P.M., \& Pikman, D. (2009). The role of promotion in supplychain management $\{\mathrm{scm}\}$. The Role of Promotion in Supply-Chain Management.

10. Lotfi, Z., Muriati, M., Sahran, S., \& Taei, A. (2013). Information Sharing in Supply Chain Management. The 4th International Conference on Electrical Engineering and Informatics (ICEEI 2013) Procedia Technology, 11, 298 - 304.

11. Gebrüder Weiss (n.d.). https://www.gw-world.com

12. LogisticsWorld (n.d.). http://www.logisticsworld.com

13. The Ministry of Economy and Sustainable Development of Georgian. (2021) Total Cargo Transportation. http://www.economy.ge/?page=ecoreview\&s $=26$

14. Mikhno, I., Koval, V., Korenyuk, P., Smutchak, Z., \& Bozhanova, V. (2021). Modeling corporate games to increase the ecological value of entrepreneurship and innovative business. E3S Web of Conferences, 255, 01027.

15. Arsawan, I.W.E., Koval, V., Rajiani, I., Rustiarini, N.W., Supartha, W.G. and Suryantini, N.P.S. (2020). Leveraging knowledge sharing and innovation culture into SMEs sustainable competitive advantage. International Journal of Productivity and Performance Management, Vol. ahead-of-print No. ahead-of-print. https://doi.org/10.1108/IJPPM-04-2020-0192

16. Petrova, M., Koval, V., Tepavicharova, M., Zerkal, A., Radchenko, A., \& Bondarchuk, N. (2020). The interaction between the human resources motivation and the commitment to the organization. Journal of Security and Sustainability Issues, 9(3), 897-907. https://doi.org/10.9770/jssi.2020.9.3(15) 